\title{
Alternative methods of differential leakage factor and windings quality estimation
}

\author{
Georgiy A. Shanshurov, Dmitriy M. Toporkov \\ Department of Electromechanics \\ Novosibirsk State Technical University \\ Novosibirsk, Russian Federation \\ d2parkoff@mail.ru
}

\begin{abstract}
Paper deals with investigation of induction electrical machines winding based on matrix description. The possibility to use such method for creation of new winding structures and properties prediction at the designing stage are discussed. The software implementing the approach suggested is also presented. Moreover, alternative methods of such windings electromagnetic features are described. The results obtained are compared with the data based on finite element analysis simulation.
\end{abstract}

Keywords-induction machines windings; matrix description; differential leakage; winding factor

\section{INTRODUCTION}

There are various graphical and analytical ways to calculate parameters of induction machines windings for solving a number of engineering problems [1-4]

The matrix description of windings permits to introduce new technical decisions in the machines windings field demonstrably and to analyze their working capacity and quality $[5,6]$. The matrix description of a winding structure, consisting of several inductive coupled electrical circuits, is used for representing the induction machine winding as an element of a matrix model [5].

The procedure proposed allows developer to estimate quality of traditional type windings and special machines windings at the designing stage by using developed software [5].

\section{WINDING MATRIX MODEL}

A winding matrix model has the following components: winding matrices, matrices of slot electromotive force (EMF) star, matrices of a winding magneto motive force, matrices of Goerges diagram.

\section{A. Winding matrix}

The variety of induction machines windings can be represented by traditional three-phase structures (Tab. 1). The following abbreviations are accepted in Tab. 1: $\mathrm{Z}$ - number of slots, $\mathrm{m}$ - number of phases, $\mathrm{p}$ - number of poles, $\mathrm{q}-$ number of slots per pole per phase, $\alpha$ - phase zone angle, $\tau$-pole pitch.

TABLE I. Three-Phase Windings Structures

\begin{tabular}{|c|c|c|c|}
\hline Par. & $\begin{array}{c}\text { Single zone } \\
\text { winding }\end{array}$ & $\begin{array}{c}\text { Double zone } \\
\text { winding }\end{array}$ & $\begin{array}{c}\text { Quadra zone } \\
\text { winding }\end{array}$ \\
\hline $\mathrm{Z}(\mathrm{m}, \mathrm{p}, \mathrm{q})$ & $\mathrm{mpq}$ & $2 \mathrm{pmq} \rightarrow \mathrm{a}, \mathrm{c}$ & $4 \mathrm{mpq} \rightarrow \mathrm{a}$ \\
\hline$\alpha$ & $120^{\circ}$ & $60^{\circ}$ & $30^{\circ}$ \\
\hline$\tau$ & $\mathrm{Z} /(2 \mathrm{p})$ & $\mathrm{Z} /(2 \mathrm{p})$ & $\mathrm{Z} /(4 \mathrm{p})$ \\
\hline $\begin{array}{c}\text { Winding } \\
\text { structure }\end{array}$ & {$\left[A_{q} B_{q} C_{q}\right]_{p}$} & {$\left[A_{q} Z_{q} B_{q} X_{q} C_{q} Y_{q}\right]_{p}$} & $\begin{array}{c}{\left[A_{q} b_{q} Z_{q} x_{q} B_{q} c_{q} X_{q}\right.} \\
\left.y_{q} C_{q} a_{q} Y_{q} z_{q}\right]_{p}\end{array}$ \\
\hline
\end{tabular}

Fig. 1 shows the matrix of three-phase single-layer doublezone winding $\|A\|_{i, j}$ :

$$
\left[A_{q} Z_{q} B_{q} X_{q} C_{q} Y_{q}\right]_{p}=A_{2} Z_{2} B_{2} X_{2} C_{2} Y_{2} p,
$$

where $i=1 \div m$ - rows number, $j=1 \div Z$ - columns number.

Matrix $\|A\|_{i, j}$ is filled with elements $a_{m i}$ which are the ratios of the turns number in certain slot $U_{m i}$ of one phase to the basic turns number with account of the current direction "+" or "-". The matrix presented in Fig 2. consists of $m$ rows and $Z$ columns. Each matrix row $\left\|C_{p=2}\right\|_{p h m}$ describes one winding phase and is called a row phase matrix.

$$
U_{n m}\left\|C_{p}\right\|=U_{n m} \begin{aligned}
& \left\|C_{p}\right\|_{p h 1} \\
& \left\|C_{p}\right\|_{p h 2} \\
& \left\|C_{p}\right\|_{p h 3}
\end{aligned}
$$

$$
\|A\|_{i, j=}=\begin{array}{lllllllllllll}
Z / m & 1 & 2 & 3 & 4 & 5 & 6 & 7 & 8 & 9 & 10 & 11 & 12 \\
2 & A & A & & & & & X & X & & & & \\
2 & & & & & B & B & & & & & Y & Y
\end{array}
$$




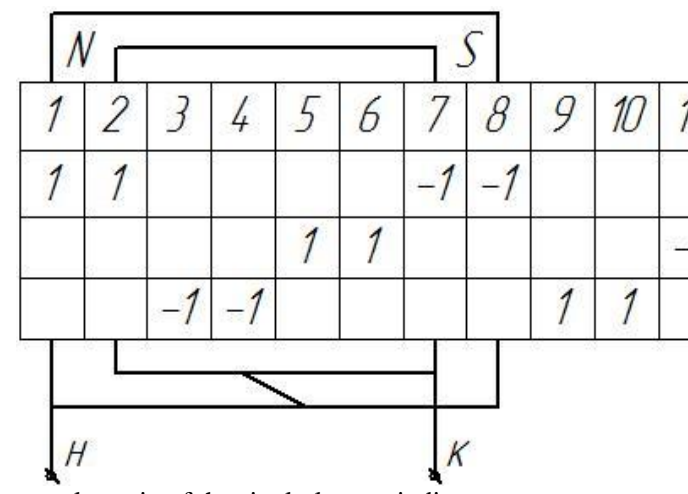

Fig. 1. Structural matrix of the single-layer winding.

\section{B. Slot electromotive force star}

A matrix EMF description is effective for working capacity analysis of winding [5]:

- determination of EMF and magnetomotive force (MMF) symmetry and phase rotation of every EMF and MMF harmonics;

- checking of the equivalence of parallel branches, i.e. agreement of corresponding EMF harmonics;

- estimation of winding factors of fundamental, high and subharmonics.

A star of slot EMFs, induced in winding can be drawn for every harmonics. Several stars, drawn on the complex plane, form slot EMFs constellation that can be represented as a matrix. Column matrix $\left\|E_{t v}\right\|$ consisted of elements $e^{j v_{i}\left(Z_{i}-1\right) \alpha_{0}}$ should be written first. Here $v_{i}-$ EMF harmonics number, $Z_{i}$ - number of slots, $\alpha_{0}=p \cdot 360 / Z$. Then EMF in matrix form [5

$$
\left\|E_{w v}\right\|_{m}=E_{t v} U_{n m}\left[\left\|C_{p}\right\|\left\|E_{t v}\right\|\right]
$$

includes matrix (1) of $m$-phase winding with normalized turns number $a_{m i}$ and EMF of turn $\left\|E_{t v}\right\|$ induced by a $v^{\text {th }}$ harmonic of flux $\Phi_{v}$. So the winding of the EMF matrix contains matrices of phase EMFs.

Estimation of windings filtering properties can be implemented with winding factor $k_{w}$ and differential leakage factor $k_{d}$ which determine the use factor $[1,5]$ :

$$
k_{u}=k_{w} \cdot 1-k_{d} .
$$

\section{Winding factor}

In addition to the main winding functions in $\mathrm{AC}$ machines winding has filtering properties weakening higher space MMF harmonics and time EMF harmonics. There are several traditional ways for higher harmonics minimization [5, 7]:

- winding groups distribution;

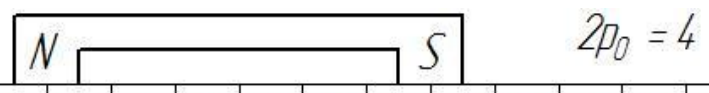

\begin{tabular}{|l|l|l|l|l|l|l|l|l|l|l|l|l|}
12 & 13 & 14 & 15 & 16 & 17 & 18 & 19 & 20 & 21 & 22 & 23 & 24 \\
\hline & 1 & 1 & & & & & -1 & -1 & & & & \\
\hline 1 & & & & & 1 & 1 & & & & & -1 & -1 \\
\hline & & & -1 & -1 & & & & & 1 & 1 & & \\
\hline
\end{tabular}

- increase of phase zones numbers and shortening of winding steps;

- usage of coils with different turns numbers.

Winding filtering properties are usually estimated with the winding factor for higher EMF and MMF harmonics (absolute $k_{w v}$ and relative $k_{w v} / k_{w 1}$ ) and with the differential leakage factor:

$$
k_{d}=x_{\sigma d} / x_{m} .
$$

Here $x_{\sigma d}$ is differential leakage inductive resistance, $x_{m}$ is main phase inductive resistance.

The winding factor for $v^{\text {th }}$ harmonic is relation of absolute amount of $\left\|C_{p}\right\|_{p h m}$ and $\left\|E_{t v}\right\|$ product to the sum of elements of matrix $\|A\|_{i, j}$ :

$$
k_{w v}=\frac{\bmod \left\|C_{p}\right\|_{p h m}\left\|E_{t v}\right\|}{\sum_{i=1}^{Z}\left|a_{m i}\right|} .
$$

\section{DIFFERENTIAL LEAKAGE FACTOR EVALUATION METHODS}

The differential leakage factor can be predicted by differential and integral methods.

\section{A. Differential method}

Differential leakage factor is determined as interrelation of higher harmonics and subharmonics winding factors and a fundamental harmonic winding factor. If there are no subharmonics in EMF curve and first harmonic is fundamental, $k_{d}$ is equal to

$$
k_{d}=\sum_{v \neq 1}^{v_{\max }}\left(\frac{K_{\mathrm{wH}}}{{ }_{\mathrm{H}} K_{\mathrm{w} 1}}\right)^{2}
$$

under every number of poles. For windings having the subharmonics differential leakage factor can be calculated as:

$$
k_{u}=k_{\text {wfund }} k_{\mathrm{pv}} \text {, }
$$

here $k_{\mathrm{p} v}=1 / k_{d}, k_{d}=k_{d f u n d} \sum_{v}^{v_{\max }}\left(\frac{v_{f u n d} k_{w v}}{\mathrm{H}_{w f u n d}}\right)^{2}$. 


\section{B. Integral method}

The integral method is based on the Goerges diagram due to the MMF matrix. The $i^{\text {th }}$ MMF matrix element value is determined as:

$$
\left(f_{i}\right)=f_{i-1}+a_{z i}
$$

Here, $i$ is a slot number, $a_{z i}$ is a value of current matrix elements, $f_{0}=0$. The Goerges diagram center in the matrix form should be transferred to the complex plane central point:

$$
\left(f_{i}\right)_{i}=\left(f_{i}\right)-r_{0}
$$

Here, $r_{0}=\frac{1}{Z} \sum_{i=1}^{Z} f_{i}$ - the Goerges diagram center coordinate on the complex plane. So the differential leakage factor:

$$
k_{d}=\left(\frac{R_{d}}{R_{G}}\right)^{2}-1
$$

Here, $R_{d}^{2}$ is inertia moment of the Goerges diagram on the complex plane projection, $R_{\mathrm{G}}=\frac{k_{\mathrm{w} 1}}{2 \pi p} \sum_{i=1}^{Z} \bmod \left(a_{z i}\right) \quad-\quad$ the Goerges diagram radius corresponding to the fundamental MMF harmonic.

\section{Example of calculation}

As an example, the calculation of $k_{d}$ for single-layer double zone winding with two pole pairs by the integral method is presented. The structural winding matrix of such winding for one pole pair is:

$\|A\|_{i, j}=U_{m}\left|\begin{array}{lllllllllllll}\frac{Z}{m} & 1 & 2 & 3 & 4 & 5 & 6 & 7 & 8 & 9 & 10 & 11 & 12 \\ 1 & 1 & 1 & & & & & -1 & -1 & & & & \\ 2 & & & & & 1 & 1 & & & & & -1 & -1 \\ 3 & & & -1 & -1 & & & & & 1 & 1 & & \end{array}\right|$

It is assumed that the numbers of turns in every slot is equal to $U_{m i}=U_{m}$, so common multiple is put outside the matrix and $\left|a_{m i}\right|=1$.

To calculate $k_{d}$, the current matrix and the MMF matrix should be built. The current matrix is drawn in two steps. The first step is to produce every element of the phase winding matrix on instantaneous current:

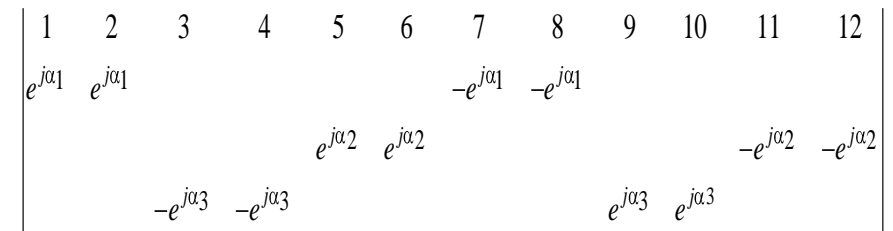

Here, $\alpha_{2}=\alpha_{1}+2 \pi / 3 ; \alpha_{3}=\alpha_{1}+4 \pi / 3$. The second step is to sum the abovementioned matrix rows. Therefore the current matrix is: $\left|\begin{array}{cccccccccccc}1 & 2 & 3 & 4 & 5 & 6 & 7 & 8 & 9 & 10 & 11 & 12 \\ e^{j \alpha_{1}} & e^{j \alpha_{1}} & -e^{j \alpha_{3}} & -e^{j \alpha_{3}} & e^{j \alpha_{2}} & e^{j \alpha_{2}} & -e^{j \alpha_{1}} & -e^{j \alpha_{1}} & e^{j \alpha_{3}} & e^{j \alpha_{3}} & -e^{j \alpha_{2}} & -e^{j \alpha_{2}}\end{array}\right|$

The MMF matrix is built by (4):

$$
\left|\begin{array}{ccccccc}
1 & 2 & 3 & 4 & 5 & 6 \\
e^{j \alpha_{1}} & e^{j \alpha 1} & 2 e^{j \alpha_{1}}-e^{j \alpha_{3}} & 2 e^{j \alpha_{1}}-e^{j \alpha_{3}} & 2 e^{j \alpha_{1}}-e^{j \alpha_{3}}+e^{j \alpha_{2}} & 2 e^{j \alpha 1}-e^{j \alpha_{3}}+e^{j \alpha_{2}} \\
7 & 8 & 9 & 10 & 11 & 12
\end{array}\right|
$$

After transferring the Goerges diagram to the complex central point, the inertia moment of the Goerges diagram can be obtained:

$$
R_{d}^{2}=\frac{1}{Z} \sum_{i=1}^{Z}\left[\operatorname{Re} f_{i}^{2}+\operatorname{Im} f_{i}^{2}\right]=\frac{1}{24} \cdot 84=3.5 .
$$

The Goerges diagram (Fig. 2) radius corresponding to the fundamental MMF harmonic is:

$$
R_{G}=\frac{k_{w 1}}{2 \pi p} \sum_{i=1}^{Z} \bmod a_{z i}=\frac{0.966}{2 \pi \cdot 2} \cdot 24=1.84 .
$$

So the differential leakage factor is equal to:

$$
k_{d}=\left(\frac{R_{d}}{R_{G}}\right)^{2}-1=0.0294 .
$$

Therefore, the use factor obtained is:

$$
k_{u}=k_{w} \cdot 1-k_{d}=0.938 .
$$

\section{Magnetomotive force Fourier analysis}

Winding filtering properties can be estimated by the Fourier analysis of an MMF curve as well. A MMF described in matrix form (5) can be introduced in the Fourier series. MMF harmonic amplitudes are determined as:

$$
F_{v}=U_{n m} \cdot I_{m} \cdot \frac{2}{v \cdot Z_{0}} L_{v},
$$

here $L_{v}$ is the resulting phase MMF of vector magnitude.

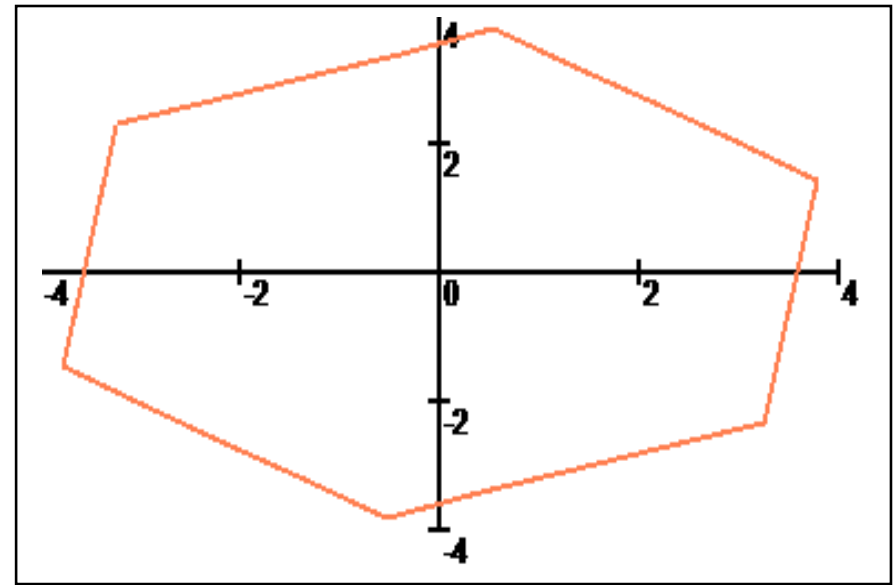

Fig. 2. The Goerges diagramm 


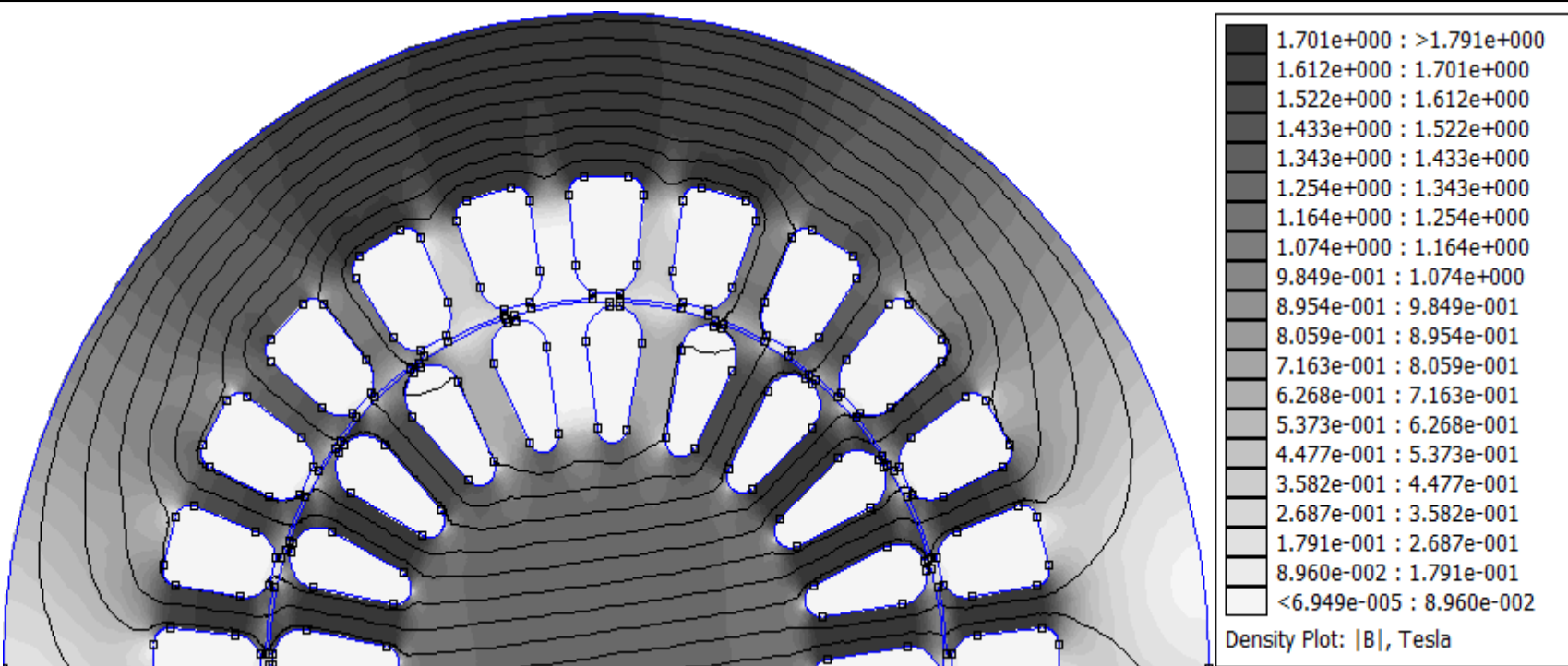

Fig. 3. Structural matrix of the single-layer winding.

If it is assumed that $U_{n m}=1$ and $I_{m}=1 \mathrm{MMF}$, harmonic amplitudes can be expressed in relative values:

$$
F_{v}=\frac{2}{v \cdot Z_{0}} L_{v} .
$$

The results for the example described above are presented in Tab. 2. There are no harmonics multiple of 2 and 3.

\section{FINITE ELEMENT METHOD VERIFICATION}

\section{A. Object of studying}

It is evident that one of the most accurate ways to calculate a winding use factor is to analyze a magnetic field distribution obtained by the Finite Element Analysis (FEA). Such approach takes into account the saturation effect and a slottooth zone geometry. The traditional general-purpose induction motor with the winding similar to the investigated above winding is taken for 2D FEA modeling. The motor has 24 slots, 1 pole pair, double zone three-phase single-layer winding.

TABLE II. CALCUlation OF THE Winding Use FACTOR

\begin{tabular}{|c|c|c|c|c|c|}
\hline $\mathbf{v}$ & $\mathbf{1}$ & $\mathbf{3}$ & $\mathbf{5}$ & $\mathbf{7}$ & $\mathbf{1 1}$ \\
\hline $\mathrm{L}_{v}$ & 11.196 & 0 & 0.804 & 0.804 & 11.196 \\
\hline $\mathrm{F}_{\mathrm{v}}$ & 1.866 & 0 & 0.0268 & 0.0191 & 0.17 \\
\hline $\mathrm{F}_{\mathrm{v}} / \mathrm{F}_{1}$ & 1 & 0 & 0.0144 & 0.0103 & 0.0909 \\
\hline$\lambda_{v}=\left(\mathrm{F}_{\mathrm{v}} / \mathrm{F}_{1}\right)^{2}$ & 1 & 0 & 0.0002 & 0.0001 & 0.0083 \\
\hline $\begin{array}{c}\mathrm{k}_{\mathrm{d}}=\Sigma \lambda_{v} \text { besides } \\
v=1\end{array}$ & \multicolumn{5}{|c}{0.0145} \\
\hline $\mathrm{k}_{\mathrm{w} 1}$ & \multicolumn{5}{|c}{0.952} \\
\hline $\mathrm{k}_{\mathrm{u}}=\mathrm{k}_{\mathrm{w} 1} \cdot\left(1-\mathrm{k}_{\mathrm{d}}\right)$ & \multicolumn{5}{|c}{} \\
\hline
\end{tabular}

\section{B. FEA modeling results}

The motor cross section with the magnetic field distribution is shown in Fig. 2. The airgap flux density curve is presented in Fig. 3. The curve obtained should be introduced into the Fourier series. Fig. 4 and Tab. 3 demonstrate the spectral content of this curve. The harmonics caused by slotting are not corresponding to the winding. Because of that there are only first 17 harmonics which can be taken into account.

The modeling was carried out under different load. This case was implemented by different current in the stator winding.

Using the data presented in Tab. 3 and formulas in Tab. 2, the use factor was calculated and the results were summarized in Tab. 4.

The field analysis under a different level of saturation shows that the results obtained by the methods suggested above are practically similar to the FEA based investigation values and the computational error is less than $1.7 \%$. So the method proposed can be useful for determination of induction motors windings parameters.

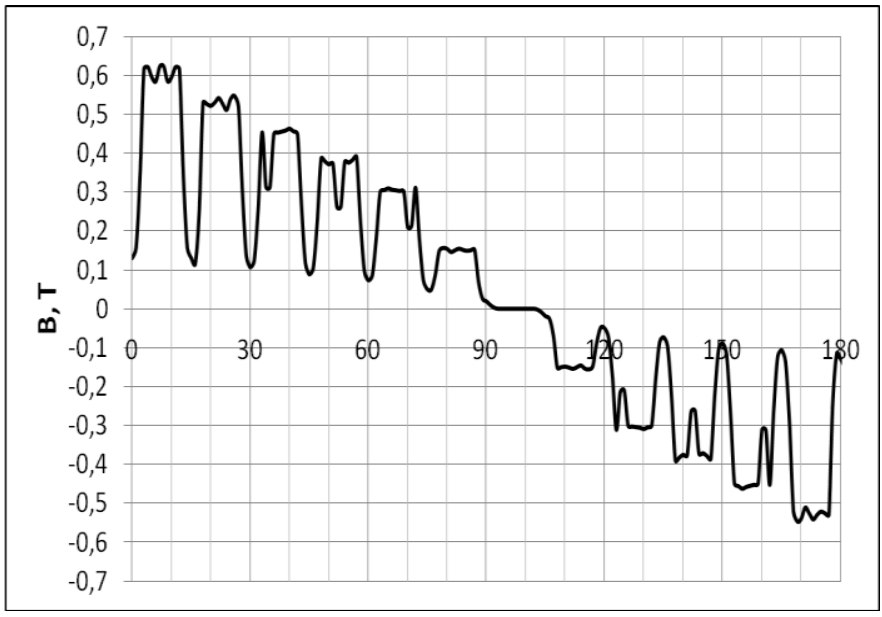

Fig. 4. Airgap flux density distribution induced by no-load current 


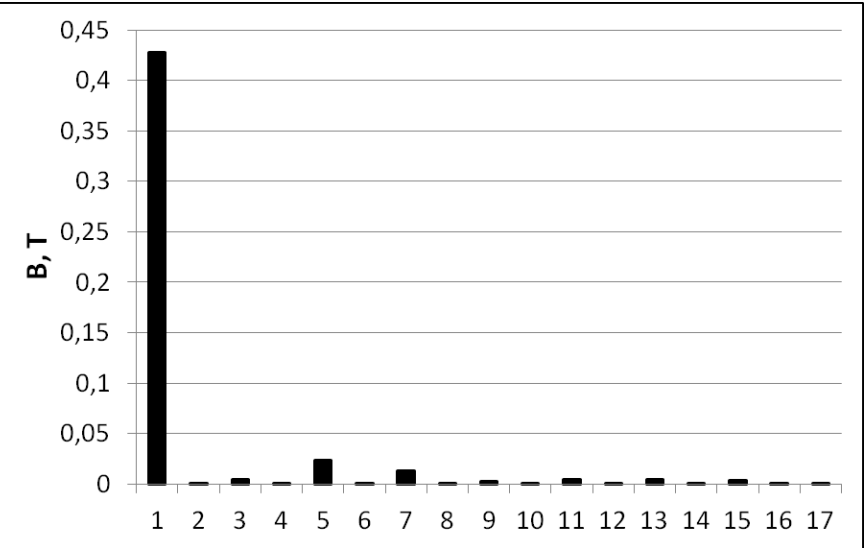

Fig. 5. Airgap flux density harmonic content induced by no-load current

TABLE III. AIRGAP FLUX DENSITY CONTENT

\begin{tabular}{|c|c|c|c|c|}
\hline $\begin{array}{c}\text { v/Current, } \\
\text { r.v. }\end{array}$ & $\mathbf{0 . 1 6 7}$ & $\mathbf{0 . 5}$ & $\mathbf{1}$ & $\mathbf{1 . 5}$ \\
\hline 1 & 0.428 & 0.7 & 0.8 & 0.838 \\
\hline 5 & 0.023 & 0.00628 & 0.00149 & 0.000926 \\
\hline 7 & 0.0132 & 0.0316 & 0.0428 & 0.044 \\
\hline 11 & 0.00445 & 0.00698 & 0.00866 & 0.0104 \\
\hline 13 & 0.0045 & 0.0112 & 0.0118 & 0.00863 \\
\hline 17 & 0.00088 & 0.00894 & 0.014 & 0.0167 \\
\hline
\end{tabular}

TABLE IV. THE WINDING USE FACTOR BY FEA

\begin{tabular}{|c|c|c|c|c|}
\hline $\boldsymbol{v} / \boldsymbol{\lambda}_{\mathbf{v}}$ & $\mathbf{0 . 1 6 7}$ & $\mathbf{0 . 5}$ & $\mathbf{1}$ & $\mathbf{1 . 5}$ \\
\hline 1 & 0.00288 & 0.00008 & 0 & 0 \\
\hline 5 & 0.000955 & 0.00203 & 0.00286 & 0.00276 \\
\hline 7 & 0.00011 & 0.0001 & 0.00012 & 0.000153 \\
\hline 11 & 0.00011 & 0.000254 & 0.0002 & 0.000106 \\
\hline 13 & 0 & 0.000161 & 0.0003 & 0.000397 \\
\hline 17 & 0.00288 & 0.00008 & 0 & 0 \\
\hline $\mathrm{k}_{\mathrm{d}}$ & 0.00406 & 0.00263 & 0.00348 & 0.00341 \\
\hline $\mathrm{k}_{\mathrm{u}}$ & 0.954 & 0.955 & 0.954 & 0.954 \\
\hline
\end{tabular}

\section{USE OF MATRIX WINDING ANALYSIS FOR MACHINE} DESIGNING ENGINEERING ANALYSIS

The methods suggested can be used to predict the main inductance of an equivalent T-circuit of the induction motor at the designing stage. An airgap length is determined as:

$$
l_{\text {Д }}=\frac{P^{\prime}}{k_{B} \cdot D^{2} \cdot Щ k_{w 1} \cdot A \cdot B_{\text {д }}},
$$

where $P^{\prime}$ is a design power, $k_{B}$ is an airgap field factor, $D$ is a stator inner diameter, Щ is a field rotational speed, $A$ is an electric loading and $B_{\text {д }}$ is an airgap flux density. A preliminary main inductive resistance value is:

$$
x_{m 1}=\frac{4 \cdot m \cdot f}{\pi} \cdot \frac{\mu_{0} \cdot \tau \cdot l_{\delta}}{k_{\mu} \cdot k_{\delta} \cdot \delta} \cdot \frac{w_{1}^{2} \cdot k_{w 1}^{2}}{p},
$$

where $f$ is a current frequency, $\mu_{0}$ is an air magnetic permeability, $\tau$ is a pole pitch, $k_{\mu}$ is a saturation factor, $k_{\delta}$ is a Carter factor, $\delta$ is an airgap width, $w_{1}$ is a phase turns number. A differential leakage permeance is:

$$
\lambda_{d}=\frac{x_{m 1} \cdot k_{d}}{4 \mu_{0} \pi f \cdot \frac{w_{1}^{2}}{p \cdot q} \cdot l_{\delta}} .
$$

A $k_{d}$ factor can be computed by one of the methods proposed. A leakage inductive resistance is equal to:

$$
x_{1}=15.8 \cdot \frac{f}{100} \cdot\left(\frac{w_{1}}{100}\right)^{2} \cdot \frac{l_{\delta}}{p \cdot q} \cdot\left(\lambda_{s 1}+\lambda_{e 1}+\lambda_{d}\right),
$$

where $\lambda_{s 1}$ is a slot leakage permeance, $\lambda_{e 1}$ is an end part leakage permeance. Finally, main inductive resistance is determined as:

$$
x_{m 1}=\frac{U_{1}}{I_{\mu}}-x_{1} .
$$

Here, $U_{1}$ is a rated phase voltage, $I_{\mu}$ is an exciting current.

\section{CONCLUSIONS}

With a foundation of the investigation carried out, it can be concluded that:

1. The matrix description of a winding gives recognition of a winding structure. This method of winding analysis permits one to evaluate EMF and MMF harmonic content, working capacity of windings, and rotation direction of a field harmonics that influence speed-torque characteristics.

2. The matrix description suggested can be used for calculation of winding parameters.

3. Estimation of a winding quality at the designing stage allows one to determine the reasonability of the technical decisions made and subsequent development of new winding structures.

4. The suggested matrix based method, the MMF curve Fourier analysis method and the Fourier analysis method of the airgap flux density curve, intended for computation of differential leakage factor and winding quality can be used for engineering designing analysis for induction machines winding parameters.

\section{References}

[1] V.P. Shuysky, Engineering analisys of eletrical machies, Leningrad: Energy, 1968.

[2] G.A. Shanshurov, "A mathematical model of a single-phase induction motor with an asymmetric stator winding", Russian Electrical Engineering. vol. 9, pp. 467-473, 2007.

[3] V.V. Bespalov, G.A. Shanshurov, "New Technical Decisions for Poleredirected windings (PRW) of One-Phase Electrical Engines", KORUS- 
99, p. 46, 1999 [The 3rd Russian-Korean International Symposium on Science and Technology, p. 791, 1999]

[4] X. Fei, "Computer model of three-phase induction machine with pole changing", J. Huazhong Univ. Sci. and Technol, vol. 36, N 1, pp. $103-$ 106, 2008.

[5] G.A. Shanshurov, Special electrical machines. Estimation of winding quality on designing stage, Novosibirsk: NSTU, 2015.
[6] G.A. Shanshurov, "Estimation of AC machines winding quality on designing stage", Electromechanics. vol. 6, pp. 9-13, 2013.

[7] I.P. Kopilov, Electrical machines designing, Moscow: Higher school, 2005 . 